\title{
WUJUD KASIH SAYANG IBU DALAM SENI PATUNG ABSTRAK
}

\author{
Aulia Darma \\ Program Studi Penciptaan Seni Patung \\ Pascasarjana Institut Seni Indonesia Yogyakarta \\ email: auliadarma1994@gmail.com
}

Diterima : 17 April 2020. Disetujui : 5 Mei 2020. Dipublikasikan : 10 Juni 2020

(C2020 - DESKOVI Universitas Maarif Hasyim Latif. Ini adalah artikel dengan akses

terbuka di bawah lisensi CC BY 4.0 (https://creativecommons.org/licenses/by/4.0/)

\begin{abstract}
ABSTRAK
Tujuan pembuatan karya akhir ini adalah memvisualisasikan tentang ungkapan kasih sayang seorang ibu dalam wujud karya patung abstrak figuratif dengan teknik cetak (cashting) dengan menggunakan lima tahapan yaitu persiapan, elaborasi, sintesis, realisasi konsep, dan penyelesaian. Setelah melakukan serangkaian proses penciptaan yang panjang maka terciptalah 7 buah patung, diantaranya: 'Permulaan', 'Penantian Yang Panjang', "'Pengorbanan Ibu', 'Kasih Sayang", 'Ungkapan Cinta Ibu', '’Mendidik', dan ''Ketulusan'. Diharapkan karya akhir bermanfaat bagi mahasiswa jurusan seni rupa, sebagai bahan apresiasi dan karya pembanding untuk menciptakan karya patung yang lebih baik di masa yang akan datang.
\end{abstract}

Kata Kunci : Ibu, Patung, Teknik Cetak (cashting)

\section{ABSTRACT}

The purpose of this final paper is to visualize the expression of mother's affection in the form of abstract figurative sculpture by printing technique (cashting) by using five stages: preparation, elaboration, synthesis, concept realization, and completion. After performing a series of long creation process then created 7 pieces of sculpture, including: " Beginnings ", " Long Waiting ", " Sacrifice Mother "," Love "," Mother Love Expression " , " Educating ", and "Sincerity ". It is hoped that the final work will be useful for art students, as an appreciation and comparative work to create better sculpture in the future.

Keywords: Mother, Sculpture, Printing Technique (cashting)

\section{PENDAHULUAN}

Ibu adalah seorang wanita yang telah merawat dan melahirkan anaknya ke dunia dengan susah payah. Pengorbanan seorang ibu kepada anaknya begitu besar. Ibu selalu menempatkan kebutuhan dan kepentingan anak-anaknya jauh di atas kebutuhan dan kepentingannya sendiri

Awal kehamilan ibu merawat si calon bayi agar dapat lahir dengan selamat. Setelah sembilan bulan ibu berjuang untuk melahirkan anaknya agar anaknya dapat lahir dengan selamat. Rasa sakit yang luar biasa hingga mempertaruhkan nyawanya. Setelah anaknya lahir, ibu selalu mengasihi, mengasuh dan membesarkan agar anaknya dapat tumbuh dengan baik.

Sikap seorang ibu kepada anaknya seharunya menjadi ibu yang bertanggung jawab dan penuh kasih sayang. Akan tetapi, banyak kejadian yang terjadi seorang ibu malah menelantarkan anaknya, menyianyiakan anaknya dan bertindak tidak selayaknya seorang ibu kepada anaknya, dan itulah yang menjadi alasan kuat penulis untuk mengangkat permasalahan tersebut karena penulis merasa hal itu merupakan masalah yang penting untuk dikemukakan. Kemudian memvisualkannya kedalam karya seni patung abstrak dengan menggunakan bahan fiber dengan teknik casting dan modeling.

Alasan memilih teknik casting dalam berkarya karena patung yang akan dibuat berukuran kecil sehingga waktu yang digunakan lebih cepat. Serta hasil karya yang didapat sama persis dengan model yang akan di buat. Penulis memilih bahan fiber sebagai material utama dalam membuat patung ibu karena ketahanannya lebih lama, ringan, dan kualitasnya lebih bagus.

Alasan lainnya memilih bentuk abstrak dalam perwujudan karya akhir karena ingin melakukan penyederhanaan bentuk terhadap objek yang dibuat. Berdasarkan alasan-alasan itulah maka judul karya akhir yaitu "Wujud Kasih Sayang Seorang Ibu dalam Karya Seni Patung Abstrak Figuratif".

Berdasarkan rumusan masalah maka tujuan pembuatan karya akhir ini adalah memvisualisasikan tentang ungkapan "kasih sayang seorang ibu dalam wujud karya patung abstrak figuratif' dengan teknik casting dan modeling dan menggunakan material fiber.

Menurut Plato, Lessing, Jj.Rousseu dalam Budiwirman (2012:27) bahwa, "Seni pada hakekatnya adalah peniruan alam dengan segala segiseginya".Sedangkan patung merupakan bagian dari 
sculpture dan termasuk seni murni. Menurut Minarsih dan agus (2012:176) menyatakan "Patung adalah karya tiga dimensional yang dapat diraba dan dilihat dari segala arah dalam kondisi rupa yang berubah-ubah. Seni patung merupakan seni memahat, mencetak, membentuk atau merakit material-material menjadi figur atau bentuk tiga dimensional".

Menurut Sofyan (2006:15) bahwa, "Ibu merupakan sosok yang paling berpengaruh pada pendidikan, kesehatan, jiwa dan badan bagi seluruh anggota keluarga, khususnya anak-anak.

Seniman acuan penulis dalam karya akhir ini, terinspirasi dari karya Dolorosa Sinaga. Dolorosa lahir di Sibolga, Sumatera Utara. Dolorosa merupakan seorang pematung perempuan di Indonesia, karyakarya patungnya kebanyakan bertemakan perempuan yang menyimbolkan ilusi, kesetiaan, krisis, solidaritas, serta perjuangan perempuan melawan kekerasan. Salah satu karya Dolorosa yang menjadi acuan penulis dalam berkarya yaitu patung seorang ibu bersama anaknya

\section{METODE PENCIPTAAN}

a. Persiapan

Pada tahap awal penulis melakukan pengamatan, dan pengumpulan data serta informasi terkait masalah-masalah yang ada di lingkungan sekitar dan mencari sumber referensi seperti buku-buku, artikel, dan media masa sebagai bahan pengamatan dan sumber informasi. kemudian mulai menelaah, melihat, dan mengamati masalah yang terdapat di lingkungan sekitar.

b. Tahap Elaborasi

Selanjutnya dalam tahap elaborasi atau pendalaman ide/gagasan. Penulis melakukan pendalaman dengan cara mencari buku-buku yang terkait dengan ide, jurnal artikel dan mencari informasi tambahan melalui internet, dan media massa.

c. Tahap Sintesis

Proses sintesis adalah proses pemaduan (campuran) berbagai pengertian atau hal sehingga menjadi kesatuan yang selaras. Disini penulis melakukan penggabungan ide/gagasan yang berasal dari berbagai sumber menjadi suatu kesatuan konsep yang matang. Gabungan antara unsur yang satu dengan unsur yang lain sehingga menghasilkan kesatuan yang selaras.

d. Realisasi konsep

\section{Membuat Sketsa}

Memilih dan mencari tujuh gerakan ibu sebagai subjek karya akhir. Kemudian membuat tujuh sketsa gerakan ibu beserta beberapa sketsa alternatifnya.

2. Bahan dan Alat

Sebelum melakukan perwujudan ide-ide seni yang harus dipersiapkan beberapa alat dan bahan yang diperlukan dalam membuat karya patung. Bahan yang digunakan dalam berkarya yaitu: Resin,
Katalis, Serat fiber, Tepung talak, Dompol, Silikon, Lem lilin dan tanah liat.

\section{HASIL DAN PEMBAHASAN}

Proses penciptaan karya akhir ini menggunakan berbagai persiapan, yaitu pengamatan dan pencarian data yang berkaitan tentang fenomena sosial yang terjadi di lingkungan sekitar, serta mencari informasi dari berbagai sumber, salah satunya melalui informasi media sosial, belajar dari karya-karya seniman maupun fakta yang dilihat di lingkungan sekitar. Pencarian ide dapat dilakukan dengan melakukan penelitian ke lapangan (studi lapangan). Sedangkan dalam perwujudannya, penulis selalu mempertimbangkan unsur-unsur seni rupa. Karena hal ini merupakan dasar dan pedoman dalam berolah estetis seorang perupa atau seniman saat sedang berkarya demi memperoleh hasil yang terbaik.

\section{Karya 1}

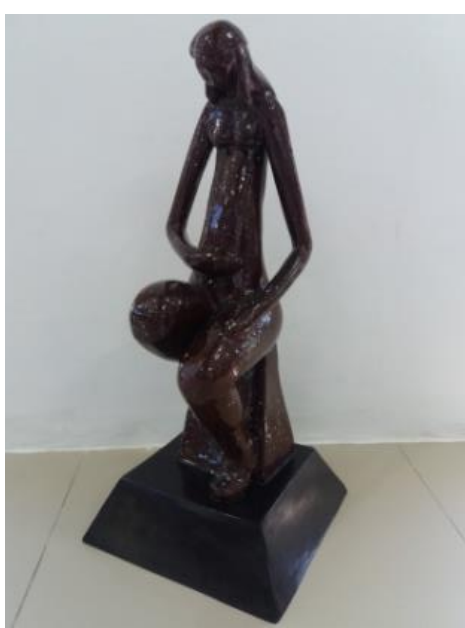

Gambar 1. Judul "permulaan"

Ukuran $60 \mathrm{~cm}$ Teknik casting

(2017)

Karya pertama ini berjudul "Permulaan" memvisualkan seorang ibu yang sedang duduk di atas batu dengan mengangkat dan melipat satu kaki. Sosok ibu berambut panjang dengan gerakan tangan yang mengelus perutnya yang sedikit membesar dengan kondisi kepala menunduk.

Karya ini menggambarkan seorang ibu yang sedang hamil muda. Konsep penulis memilih judul "Permulaan" ini sebagai salah satu yang akan dijadikan sumber ide berkarya oleh karena proses hamil muda itu sangat sulit. Seorang ibu harus berhati-hati menjaga, merawat dan memelihara cabang bayi dengan penuh kasih sayang agar tidak mengalami keguguran. Sikap merawat, memelihara calon bayi merupakan wujud kasih sayang ibu kepada anaknya.

Pesan moral yang ingin disampaikan melalui karya ini adalah hendaknya seorang ibu menjaga, dan selalu memberikan kasih sayang seutuhnya kepada 
cabang bayinya. Karena janin yang ada di perutnya merupakan karunia dari Allah SWT.

\section{Karya II}

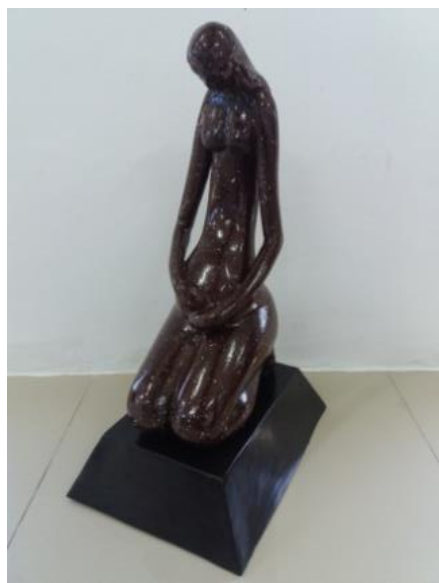

Gambar 2. Judul "Penantian yang panjang" Ukuran $60 \mathrm{~cm}$ Teknik casting 2017

Karya kedua ini, karya patung yang berjudul "Penantian yang Panjang" memvisualkan seorang ibu yang sedang duduk bersimpuh. Pada karya terdapat seorang ibu yang berambut panjang dengan gerakan kedua tangan yang mengelus perutnya yang besar sambil menundukan kepalanya menghadap kebawah.

Maksud dari gerakan ibu yang duduk sambil mengelus perutnya adalah wujud dari sebuah penantian dan sebuah pengharapan akan kehadiran sang anak kedunia. Penantian ini membutuhkan banyak kesabaran, karena ibu harus memikul berat beban dalam kandungan selama sembilan bulan. Sikap merawat, memelihara calon bayi hingga bayi tersebut lahir merupakan wujud kasih sayang ibu kepada anaknya.

\section{Karya III}

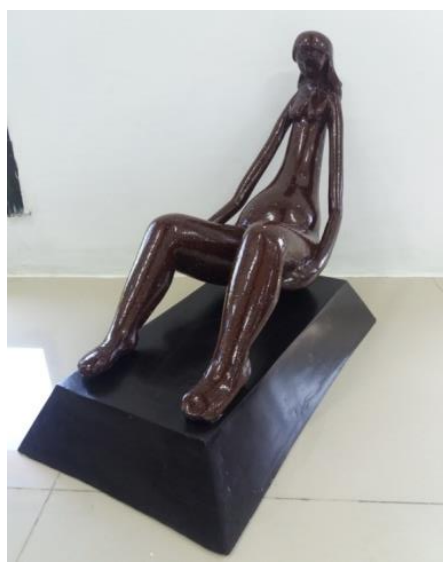

Gambar 3. Judul "pengorbanan"

Ukuran $45 \mathrm{~cm}$ Teknik casting 2017
Karya ketiga ini adalah karya patung yang berjudul "Pengorbanan Ibu" karya ini adalah bentuk visualisasi dari seorang ibu yang sedang melahirkan. Tampak perut ibu yang berukuran besar. Terlihat kedua tangan si ibu memegang paha bagian bawah dengan kuat. Tampak perut ibu yang berukuran besar. Pada karya terdapat seorang ibu yang berambut panjang sambil menundukan kepalanya menghadap kebawah.

Selanjutnya yaitu pesan moral yang ingin disampaikan melalui karya ini adalah hendaknya seorang ibu memperjuangkan kelahiran anaknya, dan selalu bersabar. Karena anak yang ada di perutnya merupakan karunia dari Allah SWT dan darah dagingnya sendiri, dan hendaknya seorang anak berbakti kepada ibunya karena wujud kasih sayang ibu kepda anaknya seperti rela berkorban, merawat, menyayangi, mendidik dan membesarkan anaknya begitu besar.

\section{Karya IV}

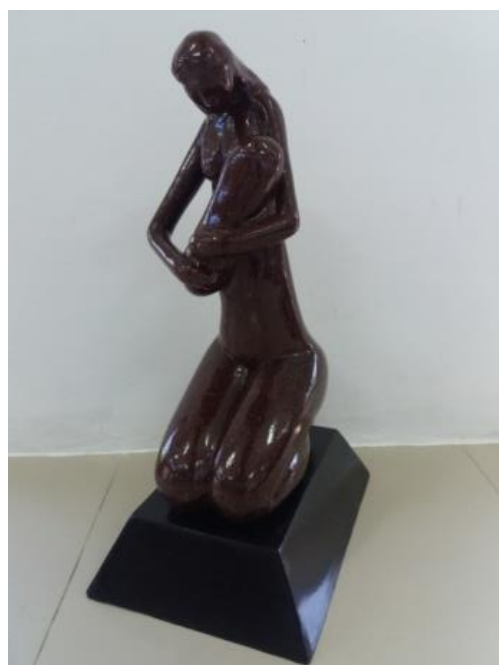

Gambar 4. Judul "Kasih syang" Ukuran $60 \mathrm{~cm}$ Teknik casting 2017

Karya keempat ini, karya patung yang berjudul "Kasih Sayang" merupakan bentuk dari visualisasi seorang ibu yang sedang duduk bersimpuh sambil menggendong bayinya. Ibu yang berambut panjang sambil menundukan kepalanya menghadap wajah anaknya. Pada karya ini terlihat ibu yang sedang menyusui anaknya dengan gerakan kedua tangan si ibu memeluk bayi dan menempelkan wajah bayi ke payudaranya.

Dapat dilihat pada karya, bentuk patung terdapat sosok ibu yang sedang menyusui mempunyai makna bahwa wujud kasih sayang ibu selalu sabar, memberikan perhatian dengan cara menyusui anaknya tak mengenal siang ataupun malam dan pesan moral yang ingin disampaikan melalui karya ini adalah hendaknya seorang ibu menyusui anaknya selama 2 tahun. Hal ini bertujuan untuk memberikan asupan gizi yang baik untuk pertumbuhan si anak 


\section{Karya V}

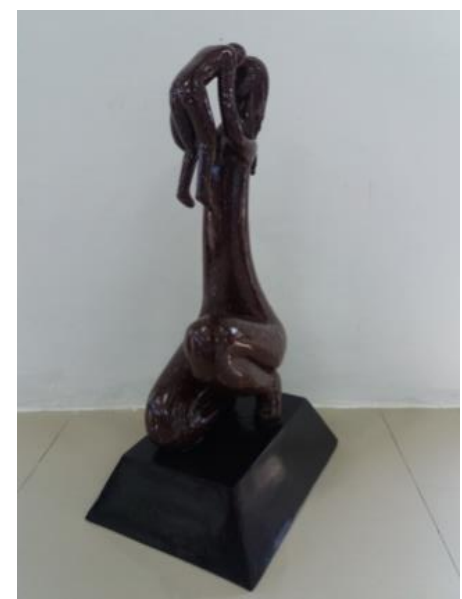

Gambar 5 Judul "Ungkapan Cinta Ibu"

Ukuran $60 \mathrm{~cm}$

Teknik casting 2017

Karya kelima ini, karya patung yang berjudul "Ungkapan Cinta Ibu" memvisualkan seorang ibu berambut panjang yang sedang mengangkat anaknya sambil mendekatkan kepala anak ke kepala si ibu. Kedua tangan antara ibu dan anak terlihat menyatu. Posisi ibu yang sedang berjongkok dengan menjinjitkan telapak kaki kiri hingga menempel pada bokong bagian kiri. Sedangkan posisi kaki kanan dengan gerakan bersimpuh. Pada figur anak posisi kaki terlihat tergantung dan posisi badan yang terangkat.

Pesan moral yang ingin disampaikan melalui karya ini adalah hendaknya seorang ibu menciptakan keharmonisan hubungan antara ibu dan anak. Sepatutnya ibu harus mengutamakan kasih sayang kepada anaknya daripada pekerjaan. Karena kasih sayang, perhatian seorang ibu sangat dibutuhkan dalam membentuk karakter si anak.

\section{Karya VI}

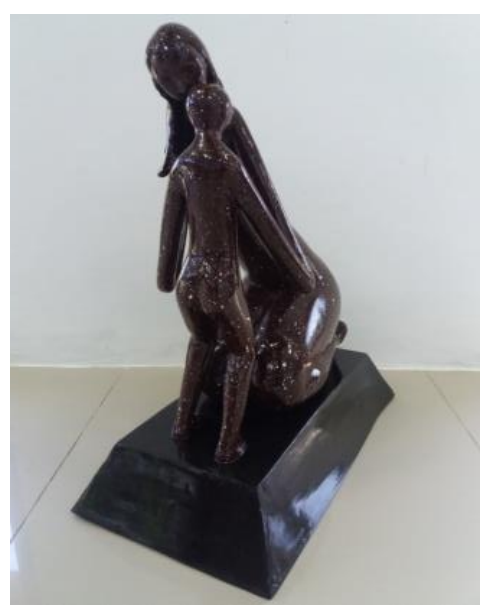

Gambar 6. Judul "Ungkapan Cinta Ibu" Ukuran $60 \mathrm{~cm}$ Teknik casting 2017
Karya ke enam ini, karya patung yang berjudul "Mendidik" memvisualkan seorang ibu yang sedang berjongkok mencium kening anaknya. Terdapat figur yang lain ada anak yang sedang memegang tangan ibunya. Seorang ibu yang berambut panjang dengan gerakan si anak menghadapkan keningnya kepada ibu dan ibu mencium kening anaknya.

Pesan moral yang ingin disampaikan melalui karya ini adalah hendaknya seorang ibu menjaga, memelihara, merawat, membesarkan, dan memberikan kasih sayang dan perhatian, serta mendidik anaknya agar berperilaku yang baik di lingkungan masyarakat. Jika si anak selalu di didik dengan cara yang baik maka anak tersebut akan tumbuh dengan baik begitupun sebaliknya.

\section{Karya VII}

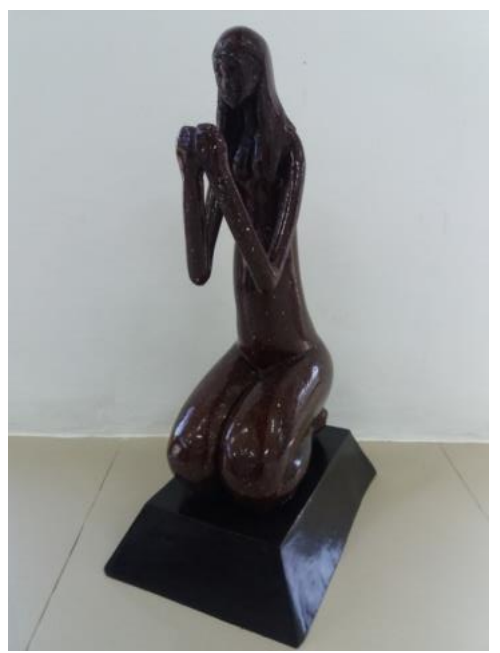

Gambar 7 Judul "Ketulusan"

Ukuran $60 \mathrm{~cm}$ Teknik casting 2017

Karya ke tujuh ini, karya patung yang berjudul "Ketulusan" memvisualkan seorang ibu yang berambut panjang terurai sedang duduk bersimpuh. Kedua telapak tangan terangkat ke atas hingga tepat di depan dada.

Karya ini terdapat gerakan seorang ibu yang sedang duduk bersimpuh. Kedua telapak tangan terangkat ke atas hingga tepat di depan dada yang mempunyai makna ketulusan seorang ibu yang selalu berdo'a agar anaknya selalu mendapatkan yang terbaik.

Pesan moral yang ingin disampaikan melalui karya ini adalah seorang ibu hendaknya tidak berputus asa dalam meminta pertolongan kepada Allah. Karena do'a ibu kepada anaknya pasti akan dikabulkan oleh Allah SWT, dan hendaklah seorang anak selalu berbakti kepada ibunya.

\section{KESIMPULAN}

Di dalam penciptaan karya akhir ini, penulis membuat tujuh buah patung ibu dengan gerakan yang 
berbeda melalui teknik cashting dengan bahan fiber. Diantara judul karya patung ibu tersebut yaitu permulaan, penantian panjang, pengorbanan ibu, kasih sayang, ungkapan cinta ibu, mendidik dan ketulusan.

Hal-hal yang menunjang proses penciptaan berdasarkan permasalahan yang terjadi di lingkungan masyarakat mengenai wujud kasih sayang ibu kepada anaknya. Karena masih banyak ibu yang tidak memberikan kasih sayang, menjalankan kewajibannya sebagai ibu kepada anaknya. Hal ini menandakan masih ada ibu yang tidak berperan sebagai orang tua yang tega menelantarkan, bahkan membunuh anak kandungnya sendiri

Kepada seluruh masyarakat umum agar dapat lebih peka mengamati permasalahan sosial dilingkungan sekitar dan meningkatkan apresiasi tentang karya-karya seni terutama yang berhubungan dengan fenomena sosial. terkhusus kepaa kaum perempuan, calon ibu-ibu.

\section{DAFTAR PUSTAKA}

Budiwirman. (2012). Seni, Seni Grafis dan Aplikasinya Dalam Pendidikan. Padang : UNP PRES

Minarsih dan Zubaidah, Agus. (2012). Seni Rupa dalam Kawasan Seni dan Budaya. Padang : UNP PRESS

Couto, Nasbahry., \& Minarsih, (2009). Seni Rupa Teori dan Aplikasi. Padang : UNP Press.

Ramanto, Muzni. (2013). Bahan Ajar Sculpture. Padang : Jurusan Seni Rupa

Sofyan. (2006). Peran Orang Tua dalam Perkembangan Anak. Jakarta : EGC 
Aulia Darma / DESKOVI : Art and Design Journal, Vol. 3, No.1, Juni 2020, 29-34

(halaman ini sengaja dikosongkan) 